\title{
Influence of tropical wind on global temperature from months to decades
}

\author{
Oleg A. Saenko ${ }^{1,2} \cdot$ John C. Fyfe ${ }^{1} \cdot$ Neil C. Swart ${ }^{1} \cdot$ Warren G. Lee $^{1} \cdot$ \\ Matthew H. England ${ }^{2,3}$
}

Received: 13 August 2015 / Accepted: 17 December 2015 / Published online: 4 January 2016

(C) The Author(s) 2016. This article is published with open access at Springerlink.com

\begin{abstract}
Using an Earth System Model and observations we analyze the sequence of events connecting episodes of trade wind strengthening (or weakening) to global mean surface temperature (GMST) cooling (or warming), with tropical ocean wave dynamics partially setting the time scale. In this sequence tropical west Pacific wind stress signals lead equatorial east Pacific thermocline depth signals which lead tropical east Pacific sea surface temperature (SST) signals which lead GMST signals. Using the anthropogenic, natural and tropical wind signals extracted from our simulations in a multivariate linear regression with observed GMST makes clear the balance that exists between anthropogenic warming and tropical wind-induced cooling during the recent warming slowdown, and between volcanic cooling and tropical wind-induced warming during the El Chichón and Pinatubo eruptions. Finally, we find an anticorrelation between global-mean temperatures in the near-surface (upper $\sim 100 \mathrm{~m}$ ) and subsurface $(\sim 100-300 \mathrm{~m}$ ) ocean layers, linked to wind-driven interannual to decadal variations in the strength of the subtropical cell overturning in the upper Pacific Ocean.
\end{abstract}

Oleg A. Saenko

Oleg.Saenko@ec.gc.ca

1 Canadian Centre for Climate Modelling and Analysis, Victoria, BC, Canada

2 ARC Centre of Excellence for Climate System, University of New South Wales, Sydney, NSW, Australia

3 Climate Change Research Centre, University of New South Wales, Sydney, NSW, Australia

\section{Introduction}

Changes in surface wind stress can have a strong influence on the ocean circulation and, hence, on climate. Our focus here is on variations of tropical winds and their impact on the global mean surface temperature (GMST) on time scales from months to decades. The smallness of Coriolis parameter near the equator implies that even small changes in the local winds can translate into large changes in the equatorial upwelling, affecting the depth of thermocline and tropical sea surface temperature (SST). The time scale of the tropical thermocline response to variations in the winds is relatively short, ranging from months to less than a year, being set by tropical ocean wave dynamics (McCreary 1978; Philander and Pacanowski 1981; Gill 1982). It is therefore expected that, to the first order, GMST would respond to a change in tropical winds in less than a year, through the associated change in the depth of thermocline. However, reproducing the observed GMST response to tropical winds in climate models presents a challenge (Douville et al. 2015). To better understand the link between tropical winds and GMST, and to identify the main components in this link in climate models, it is instructive to partition the propagation of the wind-induced signals into several stages - an approach adopted here. This includes the generation and eastward propagation of Kelvin waves along the equator and the associated changes in equatorial thermocline depth, followed by the generation of off-equatorial Rossby waves that carry the associated changes in the thermocline and SST westward, filling a wider tropical region with the wind-induced SST signals that are then expressed as changes in GMST.

On longer time scales, from years to decades, changes in the tropical Pacific winds can lead to periods of prolonged 
GMST change. For example, the evidence is that the observed slowdown in the global surface warming since about 2003 is connected to the acceleration of the Pacific trade winds through the associated cooling of the eastern tropical Pacific SST. This can be seen, for example, in climate model simulations where eastern tropical Pacific SSTs are constrained to follow their observed monthly evolution (Kosaka and Xie 2013). In this way the observed slowdown of GMST increase is reproduced whereas it is not in simulations absent this constraint (Fyfe et al. 2013; Fyfe and Gillett 2014). The recent slowdown of GMST increase is also seen in simulations where tropical surface winds are instead constrained to follow their observed decadal timescale evolution, in which case intensified trade winds accelerate the subtropical cell (STC) overturning circulation in the upper Pacific Ocean leading to a slowdown in surface warming through increased subsurface ocean heat uptake (England et al. 2014; Maher et al. 2014; Watanabe et al. 2014).

Here, we further explore the link between tropical surface wind and GMST during the well-observed period from January 1979 to December 2012. We use a climate model constrained to follow the observed evolution of tropical surface wind, running five such model simulations. These simulations are initialized with slightly different initial states but with the same observed explosive volcanic and solar variability changes and anthropogenic emissions of various gases and aerosols (e.g., greenhouse gases and sulphate aerosol precursors) and land use changes (e.g., deforestation). In addition, five such simulations are considered where the model is instead constrained to follow the observed monthly climatology of tropical surface wind. Through the use of a lagged correlation analysis we use these simulations to reveal the tropical to global sequence of events whereby tropical surface wind fluctuations in the West Pacific (WP) drive substantial month-to-month changes in GMST, with tropical ocean wave dynamics playing a key role in this process. We then use observations to identify the strong and the weak links in this sequence of events in our model simulations.

We also describe two additional sets of simulations as above but where we remove the influence of explosive volcanoes and solar variability (in a manner somewhat similar to the approach in Watanabe et al. 2013). By differencing these two sets of simulations we obtain estimates of the anthropogenic and externally-forced natural signals in GMST which we then employ in a multivariate linear regression analysis to decompose the observed time series of GMST into constituent anthropogenic, natural and tropical wind components. Here, our interest is on interannual to decadal timescales, and in particular, on how these various signals in observations combine to yield the cooling signals associated with the El Chichón and Pinatubo volcanic eruptions, as well as with the 2003-2013 slowdown of GMST increase.

We conclude our paper by illustrating the link between year-to-year changes in the strength of the STC overturning in the upper Pacific Ocean and changes of global-mean ocean temperature at various depths. We find an anticorrelation between the surface and subsurface ocean temperatures, generalizing the ideas presented in England et al. (2014) for the case of weaker-than-normal trades.

\section{Observational data}

Our analysis involves observational estimates of monthly surface wind stress, surface air temperature (SAT), and sea surface height (SSH), with the wind stress used to drive the Canadian Earth System Model (see next section). The main wind stress product used in our study is from the ERAInterim Reanalysis (Dee et al. 2011). In this reanalysis product (Fig. 1a), and in other reanalysis products (Fig. 2), the equatorial trade winds are seen to accelerate since about the 1990's. This acceleration is most pronounced in the WP region; i.e., where the tropical Pacific wind stress variability is strongest (Fig. 3). The exact cause of this acceleration, whether internally or externally generated, or in some combination, is unknown at this time. Arguments have been presented demonstrating its link to the Interdecadal Pacific Oscillation (IPO) (e.g., England et al. 2014; Maher et al. 2014), as well as to the surface warming in the Indian Ocean (Luo et al. 2012; Han et al. 2013) and in the Atlantic Ocean (McGregor et al. 2012). A recent study by Li et al. (2015) presents some further evidence suggesting that the changes of the trade wind may be attributed to the SST changes over the Atlantic Ocean.

The SAT observations used in our study are from NASA Goddard Institute for Space Studies (GISS; Hansen et al. 2010). For SSH we use the Archiving, Validation, and Interpolation of Satellite Oceanographic (AVISO) dataset (Le Traon et al. 1998) which is based on measurements from several satellites (including Envisat, TOPEX/Poseidon, Jason-1 and OSTM/Jason-2) binned in $1^{\circ} \times 1^{\circ}$ grids and averaged monthly over the period from October 1992 to December 2010.

\section{Model and experimental design}

We employ a version of the Canadian Earth System Model (CanESM2; Arora et al. 2011), updated to include a spatially-variable representation of the ocean mesoscale eddy transfer coefficient based on Gnanadesikan et al. (2006), and a parameterization of eddy-driven diapycnal mixing in the deep ocean based on Saenko et al. (2012). The model is 

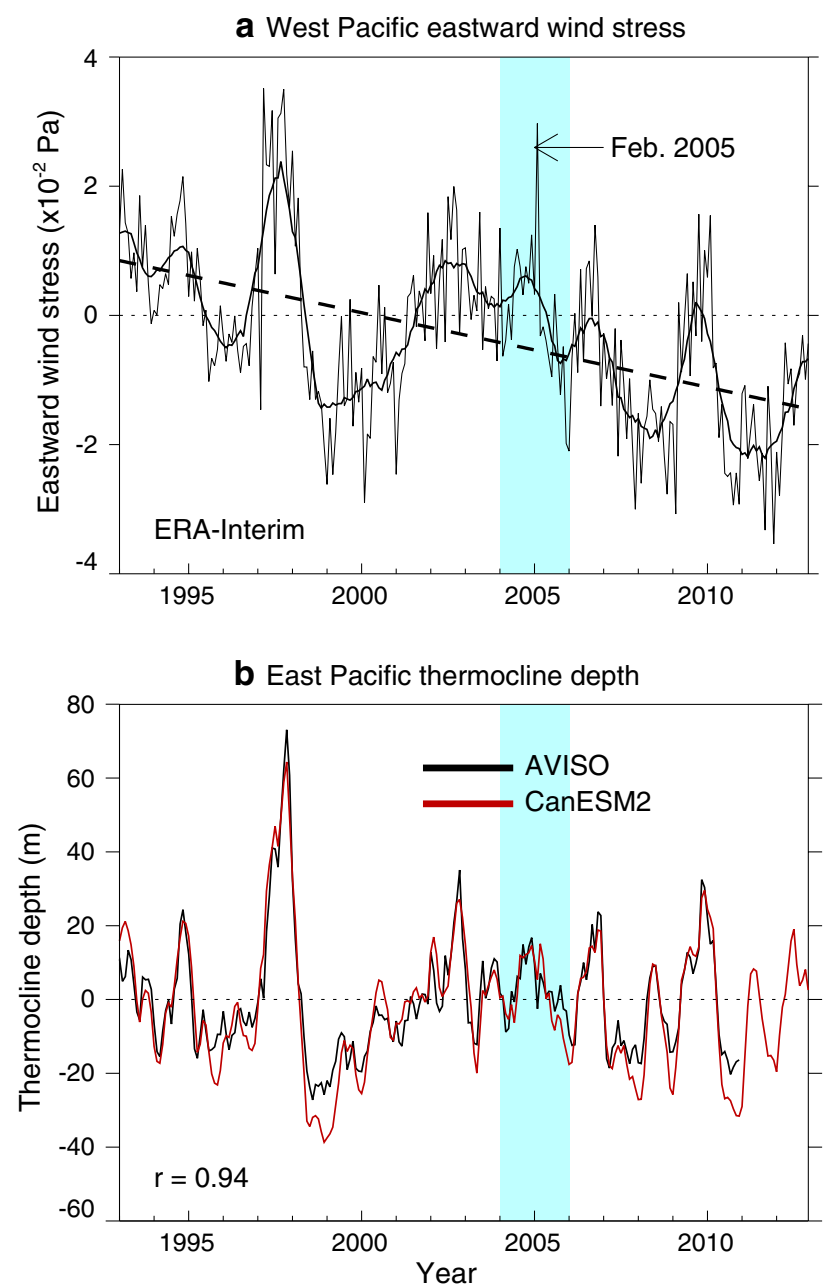

Fig. 1 Observed anomalies (relative to 1979 to 1984 climatology) of monthly eastward wind stress averaged over the West Pacific Ocean from $150^{\circ} \mathrm{E}$ to $210^{\circ} \mathrm{E}$ and from $10^{\circ} \mathrm{S}$ to $10^{\circ} \mathrm{N}$ (a). The thick curve shows 12-month running averages and the dashed line shows the best fit linear approximation. The slope of the linear trend line is $-1.2 \pm 0.6 \times 10^{-2} \mathrm{~Pa}$ per decade. Observed and simulated anomalies of equatorial thermocline depth averaged from $210^{\circ} \mathrm{E}$ to $270^{\circ} \mathrm{E}$ (b). The simulated values of thermocline depth represent the depth of the $20^{\circ} \mathrm{C}$ isotherm; the observed proxy is computed by scaling the observed sea surface height (SSH) anomalies by $\Delta \rho / \rho=5 \times 10^{-3}$ where $\Delta \rho$ is the density difference between the upper warm layer and the deeper ocean, averaged over five ensemble members. The linear correlation $(r)$ between the observed and simulated times series of thermocline depth is about 0.94 . All anomalies are relative to averages over the indicated time period which is from January 1993 to December 2012. Blue shading indicates the time period from January 2004 to December 2005 which is investigated in more detail in Fig. 5

composed of global ocean, atmosphere, sea-ice, land and carbon cycle components. The atmospheric component is a spectral model employing T63 triangular truncation with physical tendencies calculated on a 128 (longitude) $\times 64$ (latitude) (i.e., $\sim 2.8^{\circ}$ in either direction) horizontal grid and 35 vertical levels (von Salzen et al. 2013). The oceanic component is based on a version of the Geophysical Fluid

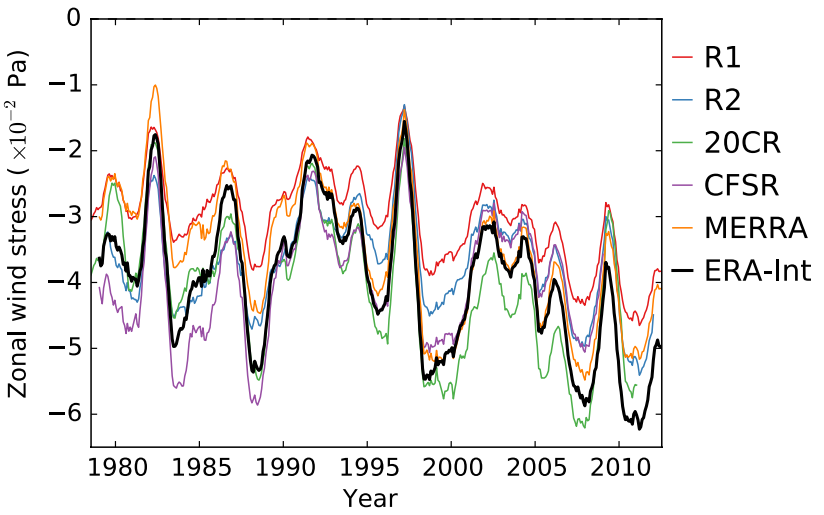

Fig. 2 As in Fig. 1 (a), except covering the whole period of analysis and using the total (rather than anomaly) wind stress data from six reanalyses: NCEP/NCAR Reanalysis 1, (R1), Kalnay et al. (1996); NCEP/DOE Reanalysis 2, (R2), Kanamitsu et al. (2002); NOAA/ CIRES Twentieth Century Reanalysis v2, (20CR), Compo et al. (2001); ERA-Interim Reanalysis, (ERA-Int), Dee et al. (2011); NCEP Climate Forecast System Reanalysis, (CFSR), Saha et al. (2010); NASA Modern Era Retrospective Analysis for Research and Applications, (MERRA), Rienecker et al. (2011). Time series are computed as 12-month running averages of monthly data

Eastward wind stress (1993-2012)

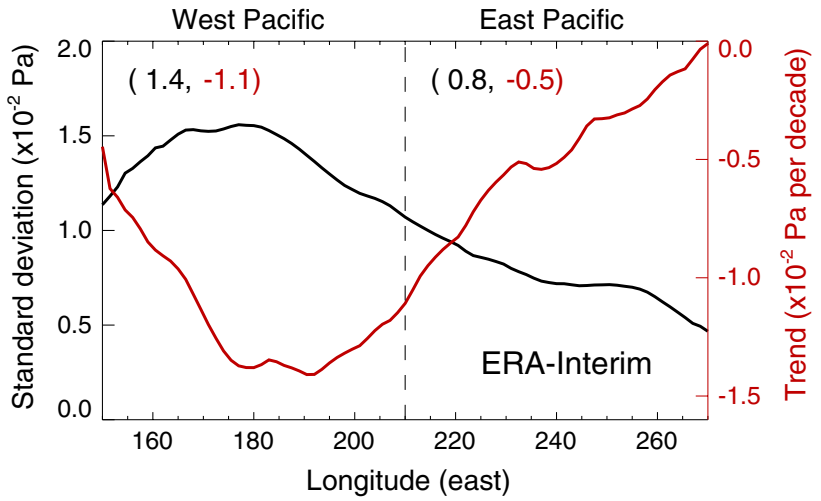

Fig. 3 Standard deviation and linear trend of observed monthly eastward wind stress averaged over the Pacific Ocean from $10^{\circ} \mathrm{S}$ to $10^{\circ} \mathrm{N}$ and over the time period from January 1993 to December 2012. All wind stress trends are statistically significant except for values east of about $260^{\circ} \mathrm{E}$. The numerical values on the left (right) in parentheses are the standard deviation and trend values averaged over the West (East) Pacific Ocean sectors. The wind stress observations are described in Dee et al. (2011)

Dynamics Laboratory Modular Ocean Model with horizontal resolution of $1.41^{\circ}$ (longitude) $\times 0.94^{\circ}$ (latitude) and 40 vertical levels (see Yang and Saenko 2012). CanESM2 reproduces many features of the observed climate and its evolution (e.g., Arora et al. 2011; Yang and Saenko 2012). For example, Fig. 1b shows that the model reproduces the observed evolution of equatorial East Pacific (EP) thermocline depth (i.e., the depth of the $20^{\circ} \mathrm{C}$ isotherm, inferred 

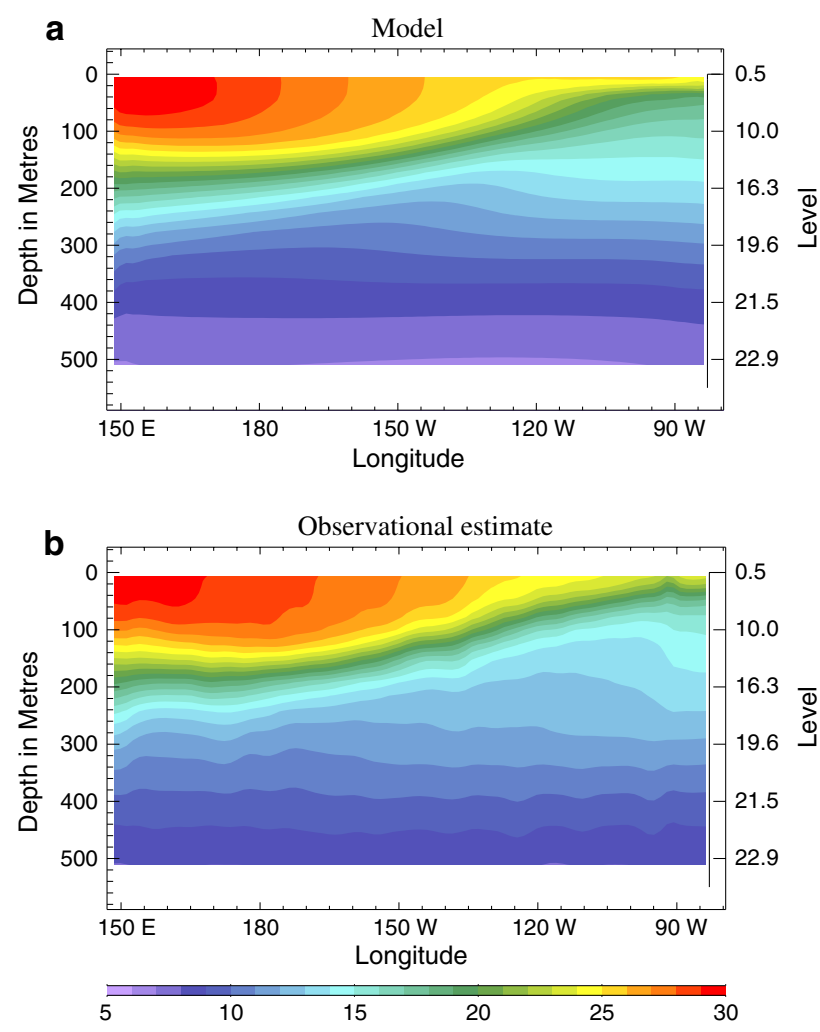

Fig. 4 Simulated (a) and observed (b) mean potential temperature along the equator in the Pacific Ocean. The observed temperature is based on the World Ocean Atlas data (Locarnini et al. 2010), interpolated on the model grid

from SSH) when driven with observed tropical surface wind stress. This suggests that the propagation of the windinduced signals by equatorial Kelvin waves is captured well by the model, which will be confirmed by a more detailed analysis in the next section. The model also simulates a reasonably good time-mean state of the ocean, including the vertical structure of temperature along the equator in the Pacific Ocean (Fig. 4).

Our model experiments branch from an 1850 to 2012 "control" simulation that used observed time-evolving external forcing (anthropogenic and natural) and wind stress at the ocean surface following the observed mean annual cycle computed from monthly ERA-Interim Reanalysis over the period 1979 to 1984 (linearly interpolated to model time step). In what follows we shall refer to it as to "climatological" wind stress, even though it represents a rather short time interval. (The latter was selected so to ensure a smooth transition from the control simulation to the climate model simulations forced with evolving wind stress, described next). In other words, the model is fully coupled but the computed wind stress is overwritten with the observed wind stress; the latent and sensible heat fluxes are computed using the wind field simulated by the model atmosphere.

Two sets of model simulations, five experiments each, were branched off the control using slightly different initial conditions in January 1979 and then following the observed time-evolving external forcing and monthly ocean surface wind stress. In the first set of simulations the observed interannual-varying monthly ocean surface wind stress was applied globally, while in the second set of simulations it was applied only in the tropical region from $35^{\circ} \mathrm{S}$ to $35^{\circ} \mathrm{N}$, with the observed fixed annual cycle of monthly ocean wind stress prescribed elsewhere, as in the control. The ensemble mean and global mean surface temperature evolution is very similar between these sets of simulations (i.e., $r \approx 0.96$ ), confirming the dominant role of tropical wind variations on global temperature evolution (England et al. 2014). Henceforth, unless stated otherwise, we will focus on the set of tropical wind simulations. To balance the five tropical wind experiments we executed four additional control experiments each branched with slightly different initial conditions from the primary control in January 1950 and then following the same external forcing and wind prescription as the primary control.

Finally, to quantify the role of natural external forcing on global surface temperature, separate from tropical wind, we repeated all of the controls and experiments described above but with the external forcing changes associated with explosive volcanoes and solar variability removed. In total, 940 years of model simulation were utilized in our study.

\section{Monthly influences}

The basic dynamics linking tropical wind variability to the slope of the thermocline depth $(D)$ along the equator can be illustrated with a simple 1.5-layer model of the ocean which dictates the following main steady-state zonal momentum balance at the equator: $g^{\prime} \partial_{x} D=\tau^{x} /(\rho H)$, where $g^{\prime}$ is reduced gravity, $\tau^{x}$ is zonal wind stress, $\rho$ is reference density and $H$ is mean depth of Pacific equatorial thermocline. For example, an equatorial thermocline that shallows towards the east (i.e., $\partial_{x} D<0$ ) can only be in balance with a westward zonal wind stress (i.e., $\tau^{x}<0$ ). If that westward zonal wind stress were to increase (i.e., $\Delta \tau^{x}<0$, as with trade wind intensification) then the thermocline must become steeper (i.e., $\partial_{x} \Delta D<0$ ) to maintain equilibrium. Taking typical values of equatorial thermocline depth $H=100 \mathrm{~m}$, reduced gravity $g^{\prime}=g \Delta \rho / \rho=0.05 \mathrm{~m} / \mathrm{s}^{2}$, and zonal length scale $L=10,000 \mathrm{~km}$ then this relationship implies that trade wind intensification of $10^{-2} \mathrm{~Pa}$ is associated with thermocline shallowing towards the east of about $20 \mathrm{~m}$. These values are consistent with the wind 


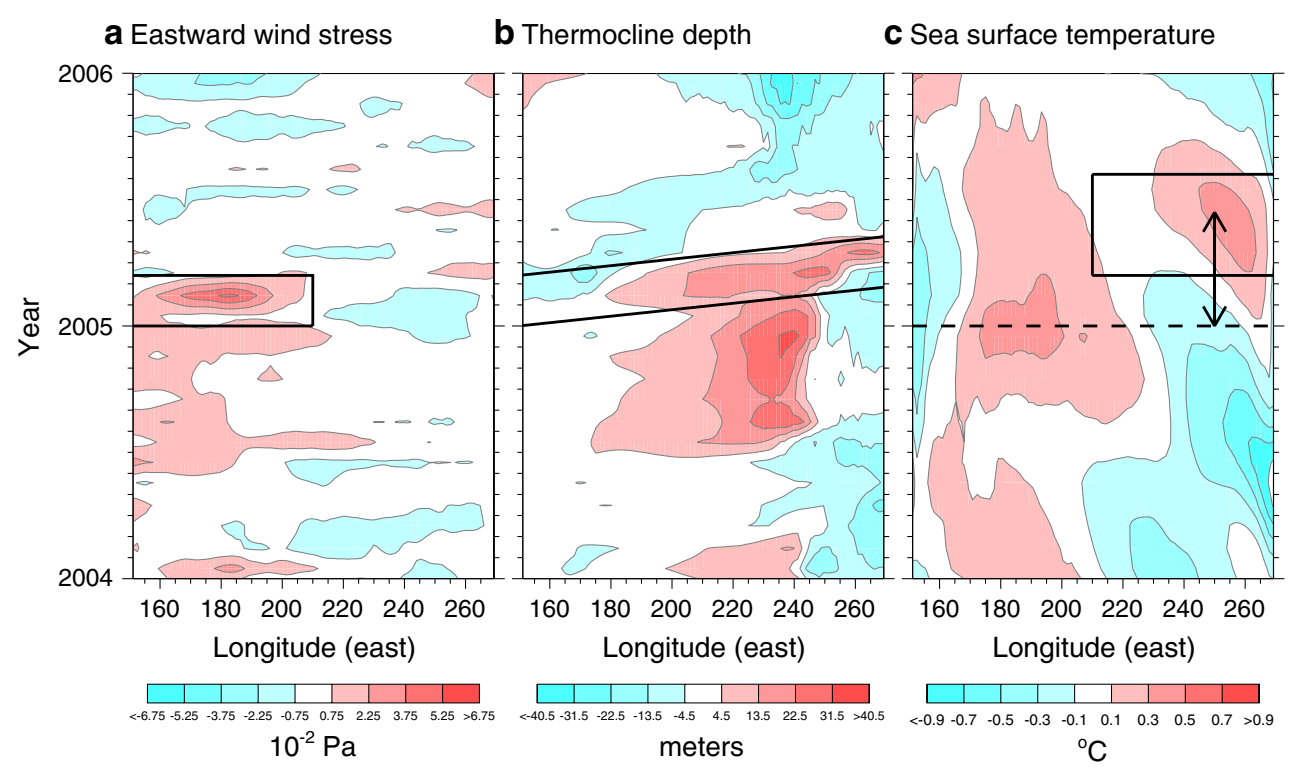

Fig. 5 Anomalies of simulated eastward wind stress averaged over the Pacific Ocean from $10^{\circ} \mathrm{S}$ to $10^{\circ} \mathrm{N}$ (a). The thick rectangle highlights a strong westerly wind stress anomaly that occurred in the West Pacific in February 2005. Anomalies of simulated equatorial Pacific Ocean thermocline depth (b). The thick lines indicate eastward propagation of a typical equatorial Kelvin wave traveling with a speed of $2.75 \mathrm{~m} \mathrm{~s}^{-1}$. Anomalies of simulated sea surface temperature averaged

stress and thermocline depth anomalies shown in Fig. 1a, b, respectively.

The equatorial thermocline adjusts to zonal wind stress fluctuations through the generation and propagation of equatorial Kelvin waves which act to deepen or shallow the thermocline (Gill 1982). This is illustrated in Fig. 5 for one of our model experiments in the case of significant trade wind weakening that occurred in February 2005. Here we see trade wind weakening in the WP (Fig. 5a) followed by an eastward propagating feature in equatorial thermocline depth leading to deepening in the EP (Fig. 5b). The propagation speed of this feature is consistent with that of a first-mode baroclinic Kelvin wave, as illustrated with the upward sloping lines in Fig. 5b. Upon reaching the eastern boundary, such Kelvin waves typically propagate north and south as coastal Kelvin waves, with some westward reflection as off-equatorial Rossby waves (McCreary 1978; Gill 1982). That such a model can capture the observed propagation speed of these off-equatorial Rossby waves has been previously demonstrated (Fyfe and Saenko 2007). In this example, the cross-basin transit time of the eastward propagating Kelvin wave and returning off-equatorial Rossby waves presumably accounts for the 6-month lag between trade wind weakening in the WP and SST warming in EP (Fig. 5c).

To explore these relationships more generally we have conducted a lag correlation analysis based on 12-month over the Pacific Ocean from $10^{\circ} \mathrm{S}$ to $10^{\circ} \mathrm{N}$ (c). The thick rectangle indicates a region of anomalous warming in the EP interpreted here as the response to the westerly wind stress anomaly that occurred 5-6 months earlier in the WP. All anomalies are relative to averages over the indicated time period which is from January 2004 to December 2005, and represent averages over five ensemble members

running averages. Figure 6a shows observed tropical WP wind stress plotted against simulated equatorial EP thermocline depth which in turn is plotted against simulated EP SST in Fig. 6b. Here the simulated variables are relative to the simulated controls. Since the experiments include wind and external forcing impacts and the controls only include external forcing impacts then we can reasonably assume that differencing effectively removes the external forcing impacts. However, the difference may still include some portion of unforced internal variability which is not related to the wind stress variability

Figure 6 shows that wind stress fluctuations are highly correlated with thermocline depth fluctuations with a lead time of about 1-month, and that the latter are, in turn, highly correlated with SST fluctuations with a lead time of about 5-months. As noted, these timescales are consistent with the cross-Pacific transit times of eastward propagating equatorial Kelvin waves and returning off-equatorial Rossby waves, although the processes involved are likely to be more complex than can be described by linear wave dynamics. To obtain a further insight, Fig. 7 shows the simulated and observed spatial patterns of correlation between EP thermocline depth and SST for lags of $-5,0$ and +5 months. In the model (left panels), the correlation in the tropical Pacific is positive at -5 months lag, but weak and centered on the WP. At 0 lag and, particularly, at +5 months lag the 
12-month running averages
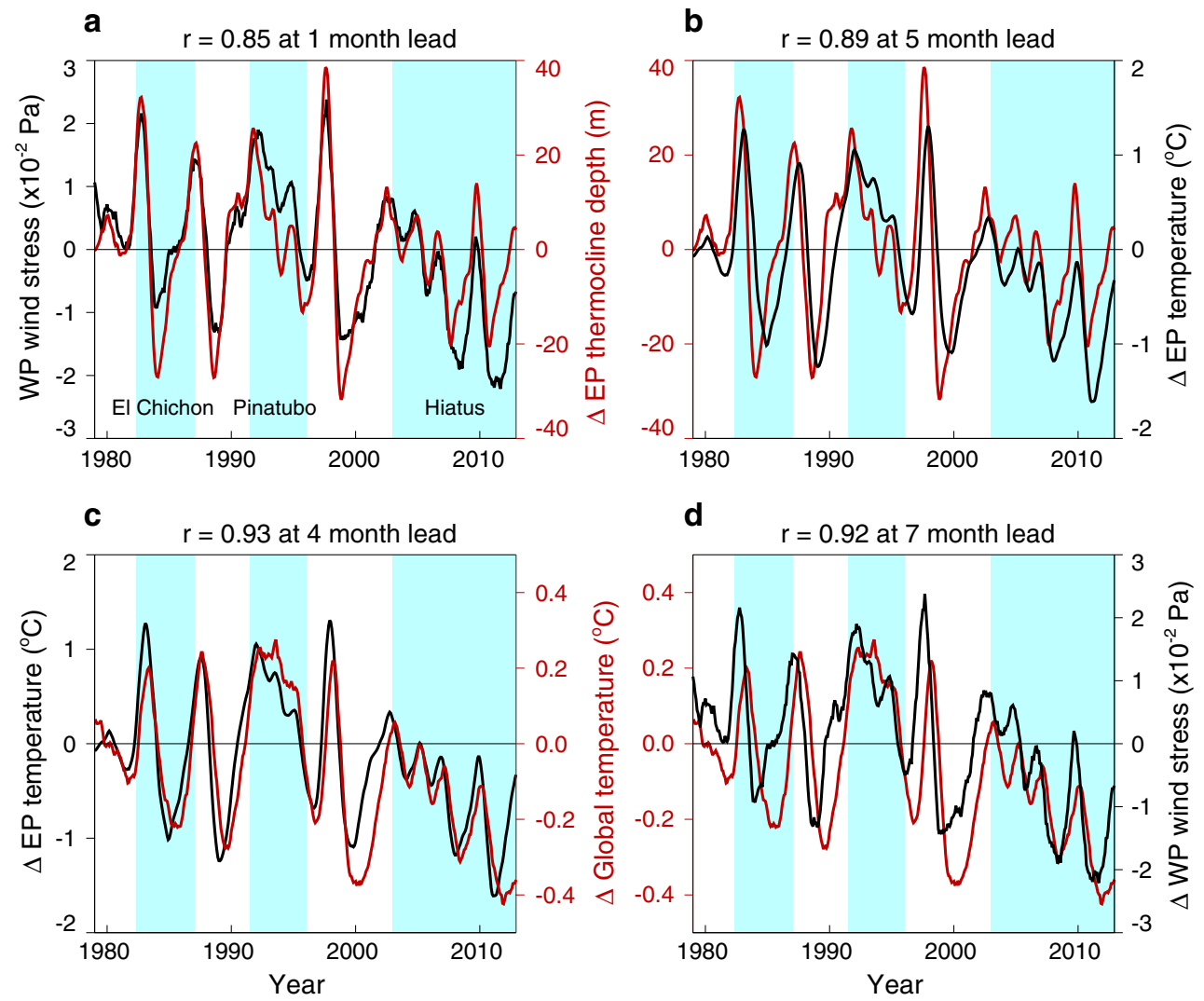

Fig. 6 Anomalies of observed eastward wind stress averaged over the West Pacific (WP) Ocean from $150^{\circ} \mathrm{E}$ to $210^{\circ} \mathrm{E}$ and from $10^{\circ} \mathrm{S}$ to $10^{\circ} \mathrm{N}$ and simulated equatorial thermocline depth averaged over the East Pacific (EP) Ocean from $210^{\circ} \mathrm{E}$ to $270^{\circ} \mathrm{E}$ (a). Anomalies of simulated equatorial thermocline depth averaged over the EP Ocean from $210^{\circ} \mathrm{E}$ to $270^{\circ} \mathrm{E}$ and sea surface temperature also averaged over the EP Ocean from $210^{\circ} \mathrm{E}$ to $270^{\circ} \mathrm{E}$ and from $10^{\circ} \mathrm{S}$ to $10^{\circ} \mathrm{N}(\mathbf{b})$. Anomalies of simulated sea surface temperature averaged over the EP Ocean from $210^{\circ} \mathrm{E}$ to $270^{\circ} \mathrm{E}$ and from $10^{\circ} \mathrm{S}$ to $10^{\circ} \mathrm{N}$ and global mean surface temperature (GMST, c). Anomalies of simulated GMST

correlation in the tropical Pacific increases and shifts eastward, with high positive values spreading beyond the tropics. Similar tendencies, while attenuated by other signals, can be seen in the observed correlation patterns (right panels).

Figure $6 \mathrm{c}$ shows that the wind-induced SST anomalies in the EP are reflected in the GMST about 4-months later, as is broadly consistent with the observational analysis presented by Trenberth et al. (2002). Figure $6 \mathrm{~d}$ closes the sequence showing that tropical WP wind stress variations produce highly-correlated GMST fluctuations peaking about 7-months later. Note that these are independent statistical estimates with no physical constraint on their additivity. The fact that they are roughly additive (though not completely) supports the sequence of cause and effect events presented in Fig. 6. and eastward wind stress averaged over the WP Ocean from $150^{\circ} \mathrm{E}$ to $210^{\circ} \mathrm{E}$ and from $10^{\circ} \mathrm{S}$ to $10^{\circ} \mathrm{N}(\mathbf{d})$. In all cases the anomalies are relative to averages over the indicated time period which is from January 1979 to December 2012. The simulated values represent ensemble-mean differences between the set of simulations with prescribed monthly-evolving tropical wind stress and the set of simulations with prescribed climatological wind stress. The blue shadings indicate the El Chichón period from April 1982 to December 1987, the Pinatubo period from January 1991 to December 1996 and the warming hiatus period from January 2003 to December 2012

To further assess these results in observations we have undertaken a lag correlation analysis of de-trended observations since 1995 when the influence of explosive volcanic activity was at a minimum and when SSH observations became available (used here to estimate the associated variations in the equatorial EP thermocline depth). In this case, observed tropical WP zonal wind stress variability accounts for about $58 \%$ of the observed GMST variance at 5-month lead, and about $66 \pm 11 \%$ of the simulated GMST variance at $6.4 \pm 1.4$ month lead (using $95 \%$ confidence intervals on the ensemble averages). The regression coefficients between tropical WP zonal wind stress and lagged equatorial East Pacific thermocline depth are $11.73 \mathrm{~m} /\left(10^{-2} \mathrm{~Pa}\right)$ and $14.05 \pm 0.06 \mathrm{~m} /\left(10^{-2} \mathrm{~Pa}\right)$ for observations and simulations, respectively. The regression coefficients between equatorial EP thermocline depth and 

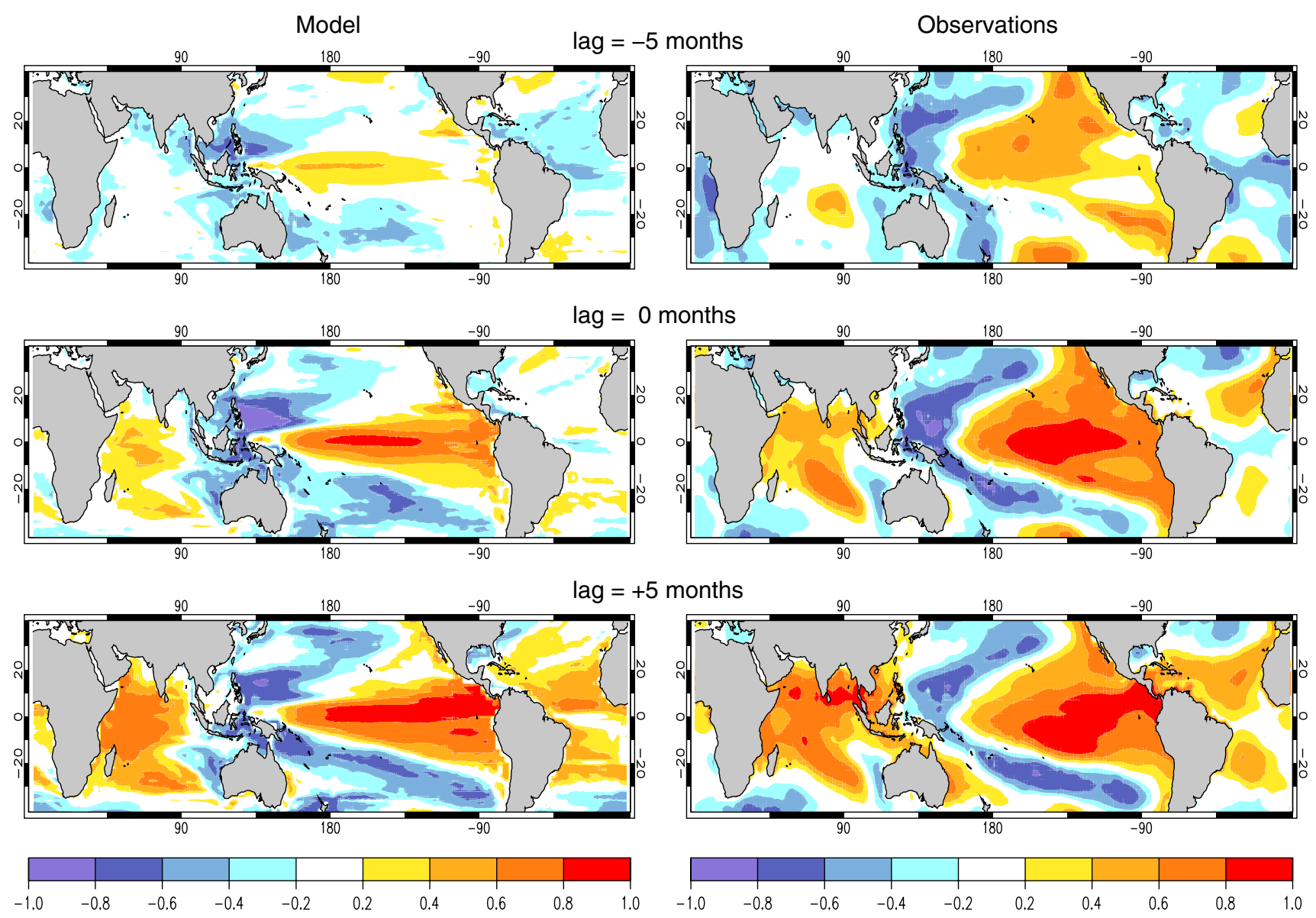

Fig. 7 Maps of correlation coefficients between the simulated (left) and observed (right) equatorial thermocline depth (ETD), averaged along the equator over the EP Ocean from $210^{\circ} \mathrm{E}$ to $270^{\circ} \mathrm{E}$, and sea surface temperature (SST) field for lags of -5 (upper panels), 0 (middle panels) and 5 (bottom panel) months. The simulated values of ETD represent the depth of the $20^{\circ} \mathrm{C}$ isotherm, whereas the observed proxy is computed using the observed SSH, as in Fig. 1 b.

lagged EP SST are $0.05^{\circ} \mathrm{C} / \mathrm{m}$ and $0.05 \pm 0.00^{\circ} \mathrm{C} / \mathrm{m}$ for observations and simulations, respectively. We note that all these observed relationships are highly statistically significant (i.e., $p<<0.05$ ) and the validity of the relationship between EP thermocline depth and SST is further apparent in Fig. 7. The good agreement between these observed and simulated regression coefficients suggests that the oceanic adjustment to the wind stress anomalies in the tropical WP, associated with propagation of equatorial Kelvin waves and off-equatorial Rossby waves described above, is captured by the model not only qualitatively but also quantitatively. Finally, the regression coefficient between EP SST and lagged GMST for observations is $0.11{ }^{\circ} \mathrm{C} /{ }^{\circ} \mathrm{C}$. This is significantly lower then the corresponding coefficient for the simulations, which is $0.23 \pm 0.05^{\circ} \mathrm{C} /{ }^{\circ} \mathrm{C}$, suggesting that the atmospheric response to the EP SST is overestimated by the model. We return to this point in Sect. 7 .

The observed SST is the GISS data (Hansen et al. 2010). The simulated correlation maps represent averages over five ensemble members. The calculations are based on monthly and 12-monthly running averages, starting from January 1995 when the influence of explosive volcanic activity was at a minimum and when SSH observations are available

\section{Interannual to decadal influences}

Here we utilize our model experiments to decompose the observed long-term evolution of GMST into anthropogenic, natural and tropical wind components. To accomplish this we perform a multivariate linear regression between observed anomalies of GMST, $T_{G L O B A L}(t)$ (as regressand), simulated anthropogenic signal, $T_{\text {ANTHRO }}(t)$ (as regressor), simulated natural signal, $T_{\text {NATURAL }}(t)$ (volcanic and solar; as regressor) and observed tropical WP zonal wind stress shifted forward by 7 -months $T_{W I N D}(t)$ (as regressor). In our calculation the regressand and regressors are based on monthly and 12-monthly running averages, respectively, and we assume that the residual, $\quad T_{\text {RESIDUAL }}(t)=T_{\text {GLOBAL }}(t)-T_{\text {ANTHRO }}(t)-$ $T_{\text {ANTHRO }}(t)-T_{\text {NATURAL }}(t)-T_{\text {WIND }}(t)$, follows a first order 
autoregressive $\mathrm{AR}(1)$ process. The applied methodology is also described in Fyfe et al. (2010).

Two comments should be made before we proceed. First, we use the observed wind stress $\left(T_{\text {WIND }}\right)$, rather than the thermocline depth in this multivariate regression analysis of decadal GMST trends. The reason for this is that on a decadal time scale, a trend in the tropical wind stress should not be expected to be fully reflected in the thermocline depth, despite the two variables showing a strong correlation on shorter time scales (Figs. 1, 6a). This is because for slowly increasing trade winds the corresponding steepening of the east-west tilt of the tropical thermocline, and the associated build up of available potential energy, should be expected to get halted at some point through a variety of instability processes operating in the tropics. Instead, the mechanism described by England et al. (2014) comes into operation on a decadal scale, wherein the slowly increasing Pacific trade winds during the last two decades (Figs. 1a, 2) led to a subduction of warm water off the equator and an upward transport of colder water across a (near steady) equatorial thermocline, thereby making the eastern tropical Pacific SST colder. Second, our separation into $T_{A N T H R O}$, $T_{N A T U R A L}$ and $T_{W I N D}$ is not perfectly clean, since anthropogenic or natural external forcing can itself influence the winds. Therefore, $T_{A N T H R O}$ or $T_{\text {NATURAL }}$ exclude any external influence on the surface circulation, since they use climatological winds, while $T_{W I N D}$, specified from observed monthly evolving winds, may include some externally forced component.

Figure 8 (top) shows the observed monthly evolution of GMST anomaly from January 1979 to February 2013. The features of interest here are the long-term warming trend, the cool anomalies associated with the El Chichón and Pinatubo eruptions, and the warming slowdown (hiatus) from about 2003 to 2013. In our multivariate regression the long-term warming trend is captured by $T_{\text {ANTHRO }}(t)=\alpha \hat{T}_{\text {ANTHRO }}(t)$ where $\hat{T}_{\text {ANTHRO }}(t)$ is the ensemble-mean GMST from the set of controls without natural external forcing changes, and $\alpha=0.57 \pm 0.04$. This value of $\alpha$ indicates that the simulated anthropogenic signal needs to be scaled down by about $40 \%$ to match the long-term trend in GMST. The natural signal is $T_{\text {NATURAL }}(t)=\beta \hat{T}_{\text {NATURAL }}(t)$ where $\hat{T}_{\text {NATURAL }}(t)$ is the ensemble-mean difference between the two sets of controls with and without natural external forcing changes, and $\beta=0.60 \pm 0.07$. This value of $\beta$ indicates that the simulated natural signal also needs to be scaled down by about $40 \%$ to produce a match with observations. Finally, the tropical wind signal is computed as $T_{\text {WIND }}(t)=\gamma \hat{T}_{\text {WIND }}(t)$ where $\gamma=(0.08 \pm 0.01) \times 10^{-2}{ }^{\circ} \mathrm{C} / \mathrm{Pa}$. If we use simulated rather than observed $T_{G L O B A L}(t)$ then in the ensemblemean $\gamma=(0.14 \pm 0.03) \times 10^{-2}{ }^{\circ} \mathrm{C} / \mathrm{Pa}$, which implies that the simulated GMST response to observed tropical wind

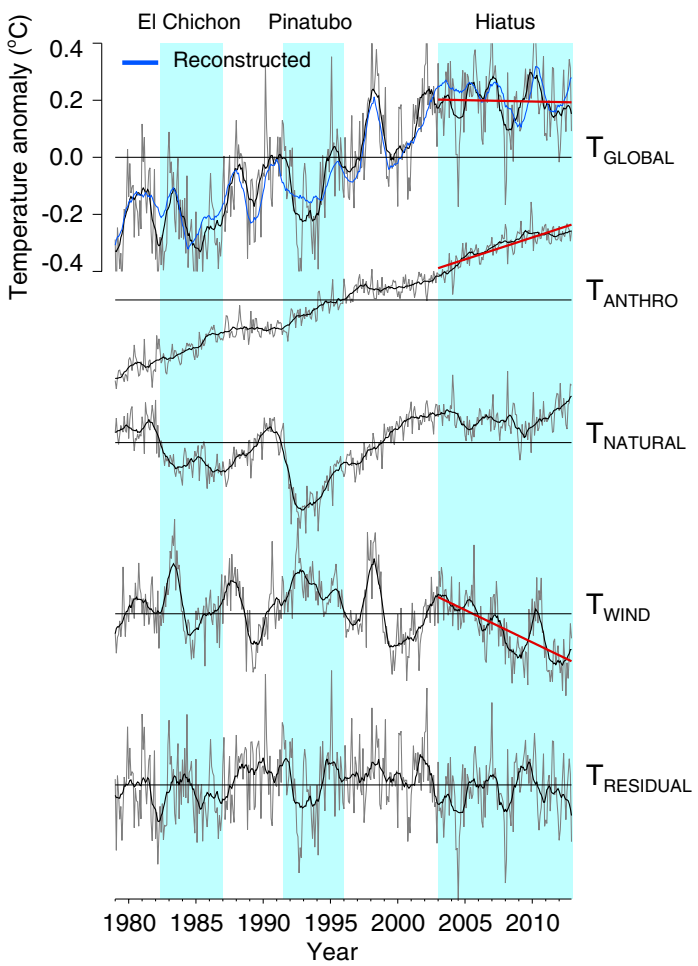

Fig. 8 Anomalies of observed monthly global surface temperature $\left(T_{G L O B A L}\right)$ which are decomposed into components due to anthropogenic forcing $\left(T_{A N T H R O}\right)$, natural forcing $\left(T_{\text {NATURAL }}\right)$, wind forcing $\left(T_{\text {WIND }}\right)$, and a residual $\left(T_{\text {RESIDUAL }}\right)$. The lower curves share the same vertical axis as the top curves but are vertically offset for presentational purposes. All anomalies are relative to the indicated time period which is from January 1979 to December 2012. The black curves are 12-month running averages of monthly values which are shown in grey. In the top panel the blue curve shows the reconstructed GMST. The linear correlation coefficient between our reconstructed GMST and the actual observed GMST is high and statistically significant $(r=0.84)$

forcing is significantly larger than observed. However, the spatial structure of the observed near-surface temperature is captured reasonably well by the model. Figure 9 illustrates this for two periods of prolonged positive and negative $T_{W I N D}$. During the former period, lasting from about 1991 to 1996, the weakening of trades was associated with El Niño-like pattern of surface warming in the central and eastern tropical Pacific (Fig. 9a, c, e; see also Watanabe et al. 2014). In contrast, during the period of recent prolonged negative $T_{W I N D}$, the strengthening of trades has led to a La Niña-like pattern of surface cooling in the central and eastern tropical Pacific (Fig. 9b, d, f; see also England et al. 2014).

Our analysis indicates that the trend in observed GMST during the warming slowdown period from 2003 to 2013 of $-0.01 \pm 0.07^{\circ} \mathrm{C}$ per decade can be interpreted as offsetting anthropogenic warming against tropical wind-induced cooling. The trend in simulated GMST during the hiatus 


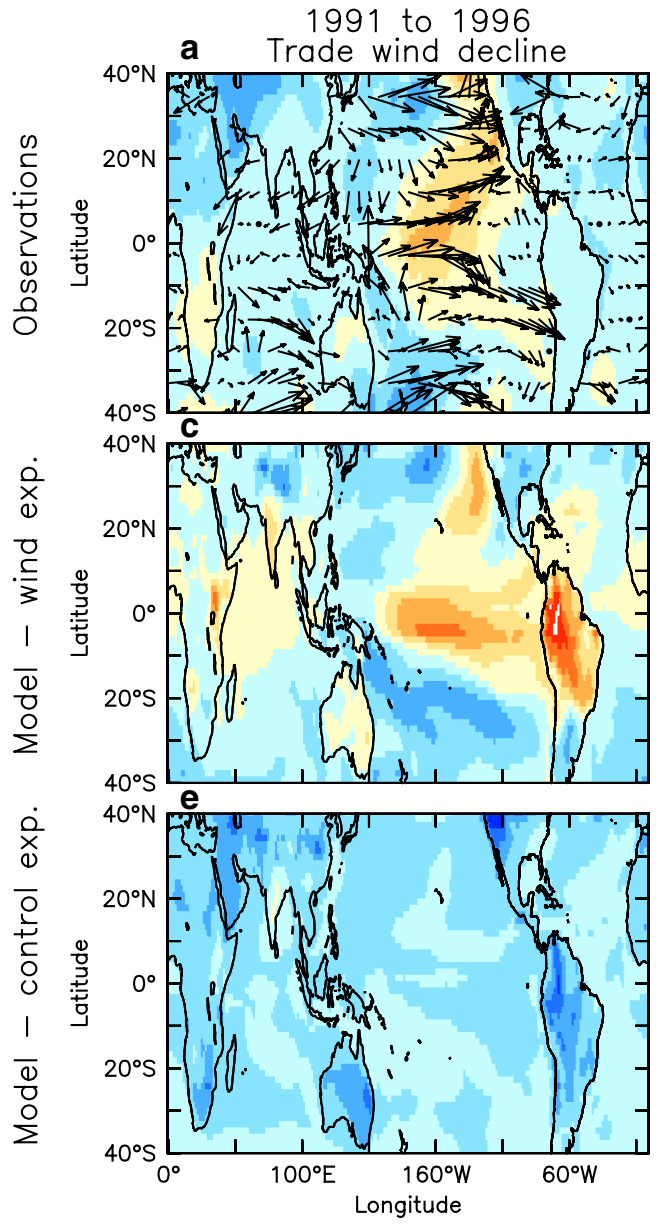

Fig. 9 Maps of surface air temperature (SAT) and wind stress anomalies: (a, b) observed and (c-f) simulated SAT, corresponding to (left) 1991-1996 and (right) 2003-2012. The observed SAT maps correspond to the GISS product (Hansen et al. 2010). The simulated SAT maps are obtained by forcing the climate model with either (c,

period of $-0.10 \pm 0.09{ }^{\circ} \mathrm{C}$ per decade also indicates no warming but with greater than observed anthropogenic warming balancing greater than observed tropical windinduced cooling. After the El Chichón and Pinatubo eruptions, volcanic cooling is partially offset by anthropogenic and tropical wind-induced warming. The tropical windinduced warming after the El Chichón and Pinatubo eruptions presumably reflects trade wind weakening associated with the 1982-1983 and 1991-1992 El Niño's, respectively.

\section{Influence on subsurface ocean}

England et al. (2014) show the influence of the recent trend in the Pacific trade winds on the ocean surface and subsurface temperatures. They find that the intensified trade winds accelerated the STC overturning circulation in the upper Pacific Ocean leading to a warming slowdown in

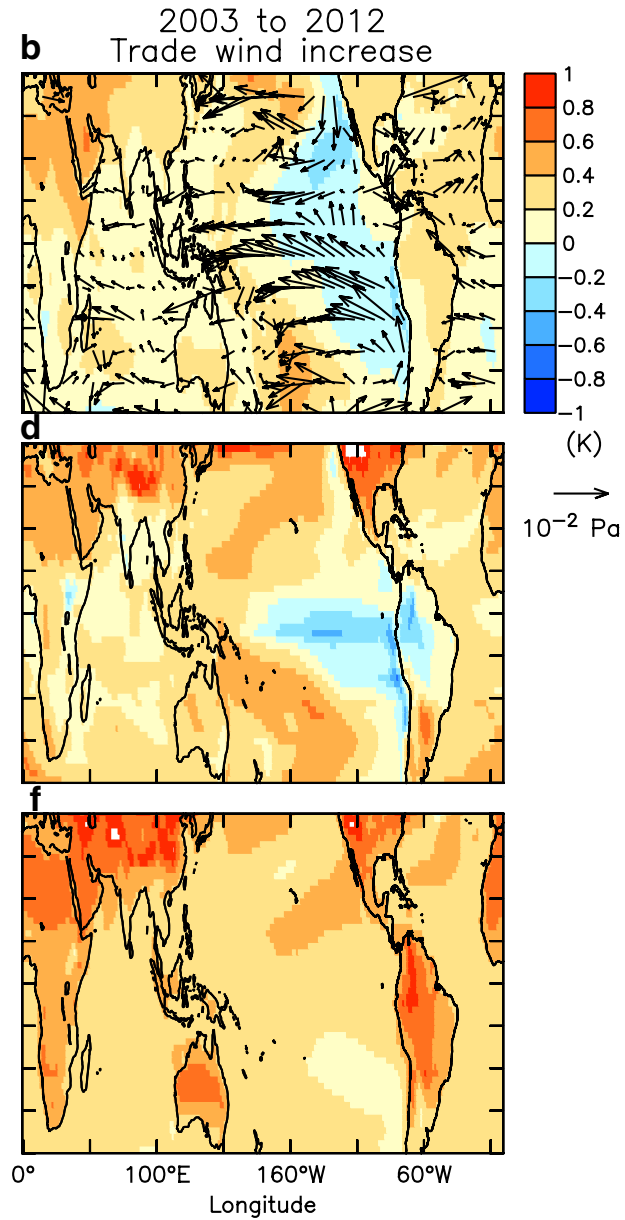

d) evolving monthly wind-stress from the ERA-Interim reanalysis (ERA-Int; Dee et al. 2011), the anomalies of which are over-plotted as vectors, or with $(\mathbf{e}, \mathbf{f})$ monthly wind-stress climatology (see Sect. 3 for details). The simulated SAT maps represent averages over five ensemble members. All anomalies are relative to 1979-2012 averages

the surface ocean and warming intensification in the subsurface ocean. Here this result is confirmed and extended for the case of trade wind weakening. In the latter case the STC overturning weakens, leading to a more pronounced warming in the surface ocean and relative cooling in the subsurface ocean, on global mean. This is illustrated in Fig. 10 using the experiments that include wind and external forcing impacts and the controls that include only external forcing impacts. It can be seen that the time intervals with stronger (weaker) than in the control STC overturning, for example between 2003-2012 (1991-1996), are characterized by cooling (warming) of the near-surface ocean and warming (cooling) of the subsurface ocean. Such an anticorrelation between the surface and subsurface ocean temperatures is consistent with the advective mechanism proposed by England et al. (2014). We also confirm a suggestion by England et al. (2014) that it is the changes in the low-latitude winds $\left(35^{\circ} \mathrm{S}-35^{\circ} \mathrm{N}\right)$ that have a major influence 

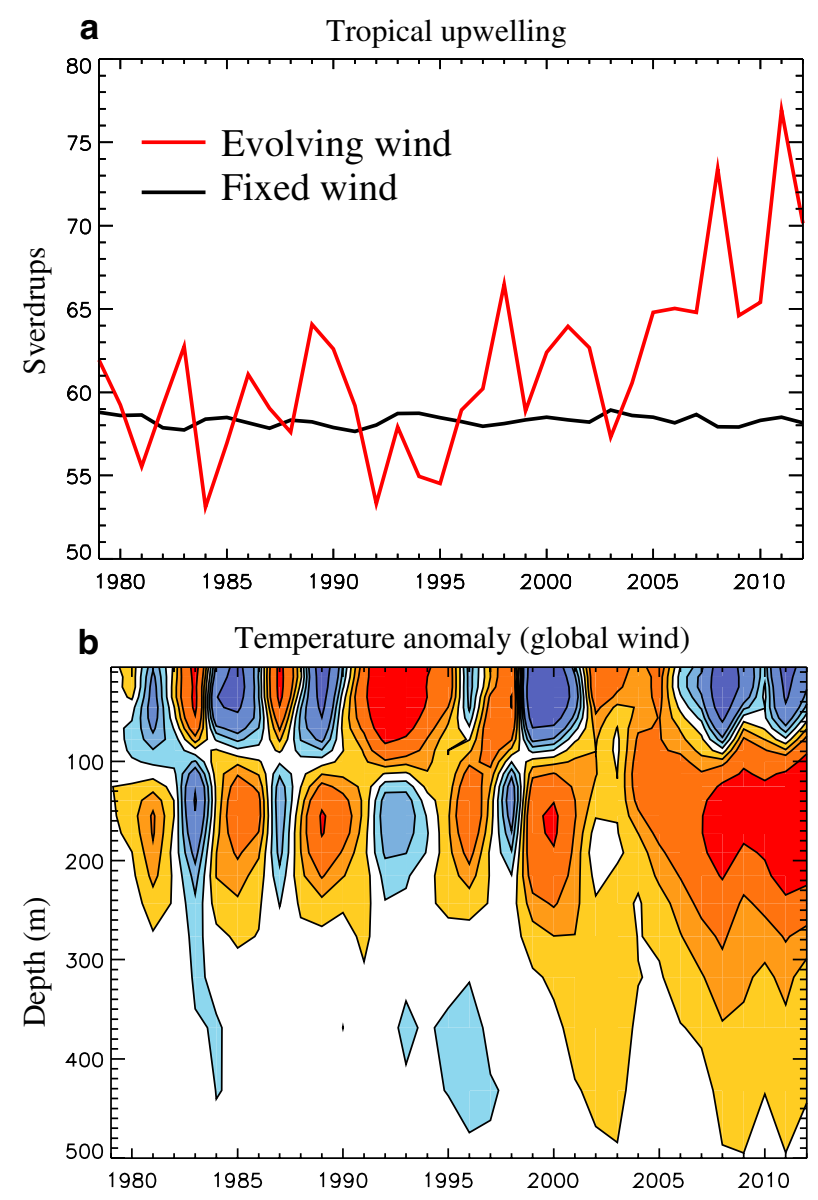

C Temperature anomaly (tropical wind)

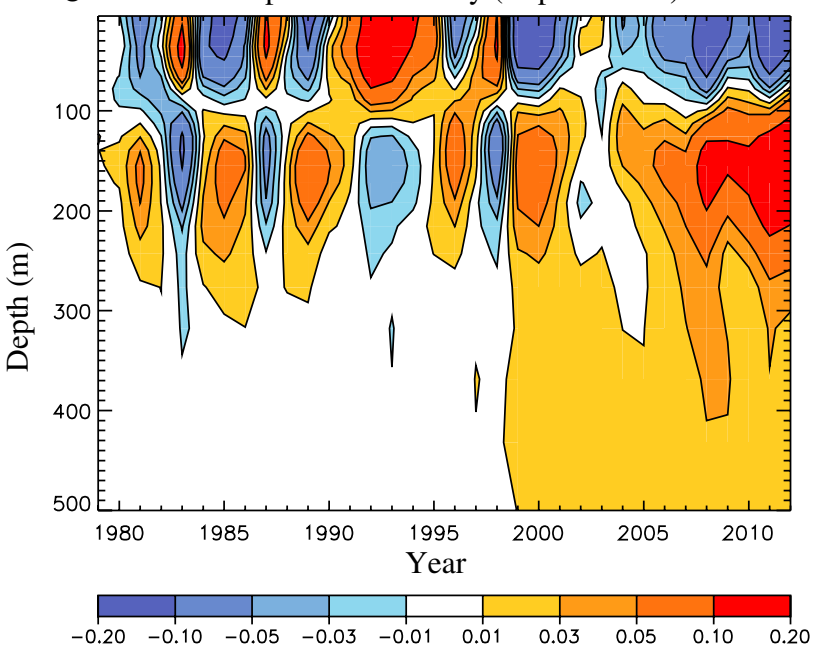

Fig. 10 a Net annual-mean tropical upwelling (in Sverdrups) in the Indo-Pacific basin which combines contributions due to the northern and southern subtropical overturning circulation cells, in the experiments with evolving (red) and fixed climatological (black) wind stresses. $\mathbf{b}$ and c Evolution of the annual-mean global ocean temperature profile anomalies (in K) given by the difference between the experiments with evolving and climatological wind stresses when the evolving wind forcing is applied $\mathbf{b}$ globally and $\mathbf{c}$ only between $35^{\circ} \mathrm{S}$ and $35^{\circ} \mathrm{N}$, with the tropical upwelling, shown in a, being almost identical in these two cases. The simulated upwelling circulations and temperature anomalies represent averages over five ensemble members on the subsurface ocean temperature (Fig. 10b, c). As expected, the external forcing impacts, by themselves, are not capable of forcing strong interannual variations in the strength of the STC overturning circulation (Fig. 10a).

\section{Discussion and conclusions}

Our observed tropical-wind constrained simulations using the Canadian Earth System Model reveal the month-tomonth sequence of events connecting episodes of trade wind strengthening (or weakening) to global mean surface temperature cooling (or warming). Key to this sequence are equatorial ocean wave dynamics which in our simulations, and observations, set an average time scale of about half a year between a given surface wind stress fluctuation in the tropical WP and a corresponding signal in GMST. Using the anthropogenic, volcanic (plus solar) and tropical wind signals extracted from our simulations in a multivariate linear regression with observed GMST makes clear the cancellation that exists between anthropogenic warming and tropical wind-induced cooling during the recent warming slowdown, and between volcanic cooling and tropical wind-induced warming during the El Chichón and Pinatubo eruptions.

A further aspect that becomes apparent through our multivariate linear regression is the fact that the simulated anthropogenic, volcanic (plus solar) and tropical windinduced signals in GMST each appear to be overestimated, relative to those seen in observations. By comparing the observed and simulated regression coefficients involved in each step of the above sequence of events, i.e. whereby tropical WP wind stress signals lead equatorial EP thermocline depth signals which lead tropical EP SST signals which lead GMST signals, we conclude that the main weakness in the simulated sequence is between fluctuations in tropical EP SST and GMST. This is demonstrated by the fact that in observations the regression coefficient between these two variables is $0.11^{\circ} \mathrm{C} /{ }^{\circ} \mathrm{C}$ at 4 month lead, while in the simulations it is $0.23 \pm 0.05^{\circ} \mathrm{C} /{ }^{\circ} \mathrm{C}$ at $3.0 \pm 1.5$ month lead. Why this is so warrants further investigation in our model, and in other models that similarly overestimate the tropical wind-induced signal in observed GMST (Douville et al. 2015).

Finally, in response to the year-to-year fluctuations in the trade winds we find an anticorrelation between the global-mean temperatures in the near-surface (upper $\sim 100$ $\mathrm{m})$ and subsurface $(\sim 100-300 \mathrm{~m})$ ocean layers. The periods of stronger (weaker) than normal trades, with the associated strengthening (weakening) of the STC overturning in the upper Pacific Ocean, correspond to cooling (warming) in the surface ocean and warming (cooling) in the subsurface ocean. 
Acknowledgments Comments from three reviewers have greatly improved the manuscript. We also thank Jim Christian and Bill Merryfield for comments on an early draft. The observational data are obtained from: GISS: http://data.giss.nasa.gov/gistemp/; ERAInterim: http://www.ecmwf.int/en/research/climate-reanalysis/erainterim; SSH: http://podaac.jpl.nasa.gov

Open Access This article is distributed under the terms of the Creative Commons Attribution 4.0 International License (http://creativecommons.org/licenses/by/4.0/), which permits unrestricted use, distribution, and reproduction in any medium, provided you give appropriate credit to the original author(s) and the source, provide a link to the Creative Commons license, and indicate if changes were made.

\section{References}

Arora VK, Scinocca JF, Boer GJ, Christian JR, Denman KL, Flato GM, Kharin VV, Lee WG, Merryfield WJ (2011) Carbon emission limits required to satisfy future representative concentration pathways of greenhouse gases. Geophys Res Lett 38:L05805

Compo GP et al (2001) The twentieth century reanalysis project. Q J Roy Meteorol Soc 137:1-28

Dee DP et al (2011) The ERA-interim reanalysis: configuration and performance of the data assimilation system. Q J R Meteorol Soc 137:553-597

Douville H, Voldoire A, Geoffroy O (2015) The recent global-warming hiatus: what is the role of pacific variability? Geophys Res Lett 42:880-888

England MH et al (2014) Recent intensification of wind-driven circulation in the pacific and the ongoing warming hiatus. Nat Clim Change 4:222-227

Fyfe JC, Gillett NP, Thompson DWJ (2010) Comparing variability and trends in observed and modelled global-mean surface temperature. Geophys Res Lett 37:L16802

Fyfe JC, Gillett NP, Zwiers FW (2013) Overestimated global warming over the past 20 years. Nat Clim Change 3:767-769

Fyfe JC, Gillett NP (2014) Recent observed and simulated warming. Nat Clim Change 4:150-151

Fyfe JC, Saenko OA (2007) Anthropogenic speed-up of oceanic planetary waves. Geophys Res Lett 34:L10706

Gnanadesikan A et al (2006) GFDL's CM2 global coupled climate models. Part II: the baseline ocean simulation. J Clim 19:675-697

Gill AE (1982) Atmosphere-ocean dynamics. Academic Press, New York

Hansen J, Ruedy R, Sato M, Lo K (2010) Global surface temperature change. Rev Geophys 48:RG4004

Han W et al (2013) Intensification of decadal and multi-decadal sea level variability in the western tropical pacific during recent decades. Clim Dyn 43:1357-1379

Kalnay E et al (1996) The NCEP/NCAR 40-year reanalysis project. Bull Am Meteorol Soc 77:437-471
Kanamitsu M, Ebisuzaki W, Woollen J, Yang S-K, Hnilo JJ, Fiorino M, Potter GL (2002) NCEP-DOE AMIPII reanalysis (R-2). Bull Am Meteorol Soc 83:1631-1643

Kosaka Y, Xie S-P (2013) Recent global-warming hiatus tied to equatorial pacific surface cooling. Nature 501:403-407

Le Traon P-Y, Nadal F, Ducet N (1998) An improved mapping method of multi-satellite altimeter data. J Atmos Ocean Technol 15:522-534

Li X, Xie S-P, Gille ST, Yoo C (2015) Atlantic-induced pan-tropical climate change over the past three decades. Nat Clim Change: doi:10.1038/nclimate 2840

Locarnini RA et al (2010) World ocean atlas 2009, vol 1: temperature. In: Levitus S (ed) NOAA atlas NESDIS 68. U.S. Government Printing Office, Washington, D.C., p 184

Luo JJ, Sasaki W, Masumoto Y (2012) Indian Ocean warming modulates Pacific climate change. Proc Natl Acad Sci (USA) 109:18701-18706

Maher N, Sen Gupta A, England MH (2014) Drivers of decadal hiatus periods in the twentieth and twenty first centuries. Geophys Res Lett 41:5978-5986

McCreary JP (1978) Eastern tropical ocean response to changing wind systems. In: Review papers of equatorial oceanography - FINE Workshop Proceedings. Nova NYIT University Press Chapter 7

McGregor S, Sen Gupta A, England MH (2012) Constraining wind stress products with sea surface height observations and implications for Pacific Ocean sea level trend attribution. J Clim 25:8164-8176

Philander SGH, Pacanowski RC (1981) Response of equatorial oceans to periodic forcing. J Geophys Res 86:1903-1916

Rienecker MM et al (2011) MERRA: NASA's modern-era retrospective analysis for research and applications. J Clim 24:3624-3648

Saenko OA, Zhai X, Merryfield WJ, Lee WG (2012) The combined effect of tidally and eddy-driven diapycnal mixing on the largescale ocean circulation. J Phys Oceanogr 42:526-538

Saha S et al (2010) The NCEP climate forecast system reanalysis. Bull Am Meteorol Soc 91:1015-1057

Trenberth KE, Caron JM, Stepaniak DP, Worley S (2002) Evolution of El Niño-southern oscillation and global atmospheric surface temperatures. J Geophys Res 107:4065

von Salzen K, Scinocca JF, McFarlane NA, Li J, Cole JNS, Plummer D, Verseghy D, Reader MS, Ma X, Lazare M, Solheim L (2013) The Canadian fourth generation atmospheric global climate model (CanAM4). Part I: representation of physical processes. Atmos-Ocean 51:104-125

Watanabe M, Kamae Y, Yoshimori M, Oka A, Sato M, Ishii M, Mochizuki T, Kimoto M (2013) Strengthening of ocean heat uptake efficiency associated with the recent climate hiatus. Geophys Res Lett 40:3175-3179

Watanabe M, Shiogama H, Tatebe H, Hayashi M, Ishii M, Kimoto M (2014) Contribution of natural decadal variability to global warming acceleration and hiatus. Nat Clim Change 4:893-897

Yang D, Saenko OA (2012) Ocean heat transport and its projected change in CanESM2. J Clim 25:8148-8163 